\title{
Characterization of Nanocarbon Copper Composites Manufactured in Metallurgical Synthesis Process
}

\author{
TADEUSZ KNYCH, PAWEł KWAŚNIEWSKI, GRZEGORZ KIESIEWICZ, \\ ANDRZEJ MAMALA, ARTUR KAWECKI, and BEATA SMYRAK
}

\begin{abstract}
Currently, there is a worldwide search for new forms of materials with properties that are significantly improved in comparison to materials currently in use. One promising research direction lies in the synthesis of metals containing modern carbon materials (e.g., graphene, nanotubes). In this article, the research results of metallurgical synthesis of a mixture of copper and two different kinds of carbon (activated carbon and multiwall carbon nanotubes) are shown. Samples of copper-carbon nanocomposite were synthesized by simultaneously exposing molten copper to an electrical current while vigorously stirring and adding carbon while under an inert gas atmosphere. The article contains research results of density, hardness, electrical conductivity, structure (TEM), and carbon decomposition (SIMS method) for the obtained materials.
\end{abstract}

DOI: $10.1007 / \mathrm{s} 11663-014-0046-7$

(C) The Author(s) 2014. This article is published with open access at Springerlink.com

\section{INTRODUCTION}

COMMON metallic materials have a well-known set of basic properties. The mechanical properties of different base materials such as $\mathrm{Cu}, \mathrm{Al}, \mathrm{Mg}, \mathrm{Sn}, \mathrm{Zn}$ can be increased in various ways, e.g., by alloying materials with different elementary substances, by plastic working, heat treatment and thermo-mechanical treatment of obtained alloys. Those methods are well understood and commonly used all over the world.

After the discovery of new carbon forms (graphene and carbon nanotubes), many researchers pursued the idea of combining them with metals. This idea assumes that the addition of nanocarbon will increase the useful properties of existing materials (metals). ${ }^{[1-6]}$ In the last few years, a new method has emerged to incorporate nanocarbon into metals such as $\mathrm{Cu}, \mathrm{Al}, \mathrm{Ag}$, $\mathrm{Au}, \mathrm{Sn}, \mathrm{Zn}$, and $\mathrm{Pb}$. It is being reported that those composites have higher electrical and mechanical properties, corrosion resistance, thermal conductivity, and other properties. $^{[7,8,13-18]}$ The inventor of the metallurgical production method of nanocomposite materials called "Covetic" is Third Millennium Materials, LLC (Dayton, Ohio). Historically, the incorporation of carbon into metals that are not strong carbide formers (like $\mathrm{Al}, \mathrm{Cu}, \mathrm{Ag}, \mathrm{Au}, \mathrm{Sn}, \mathrm{Zn}$, and $\mathrm{Pb}$ ) has been technologically difficult because of low carbon wettability. Covetic processing, by contrast, provides a straightforward method to incorporate nanocarbon into these metals. This process has only recently been publicized,

TADEUSZ KNYCH, Full Professor, and PAWEŁ KWAŚNIEWSKI, GRZEGORZ KIESIEWICZ, ANDRZEJ MAMALA, ARTUR KAWECKI, and BEATA SMYRAK, Assistant Professors, are with the AGH University of Science and Technology, Kraków, Poland. Contact e-mail: gk@agh.edu.pl

Manuscript submitted August 12, 2013.

Article published online March 14, 2014. development by the inventors is still in its early stages, and our experimental work is the first known independent replication of the method.

There are other methods to synthesize metal-carbon composites, e.g., powder metallurgy, thermal spray, electrochemical deposition and friction stir additive processing. ${ }^{[1-8,10,19]}$ The subject of metal-carbon composites has been described in some publications. In Reference 11, the authors claimed that it is possible to obtain an increase of electrical conductivity (about $10 \mathrm{pct}$ ) of copper-carbon composites vs pure copper. In Reference 9, the author shows an increase of about 15 pct in electrical conductivity of a copper-carbon composite, compared to pure copper. This material was obtained through a chemical deposition process of copper and graphene. In Reference 4, the authors reported increases in hardness of 10 to 70 pct for various combinations of $\mathrm{Cu}$ powder, which were deposited with graphite, graphene, and carbon nanofibers.

In this paper, we describe our research to independently reproduce the covetic process, and to verify the successful conversion of the carbon to strongly bound, stable nanocarbon in the melt. It is known that carbon solubility in copper is very low under equilibrium conditions at elevated temperatures. ${ }^{[12]}$ Nevertheless, according to the inventors of the covetic process ${ }^{[7,8]}$ the carbon content of copper can be increased well beyond thermodynamic equilibrium using special production conditions. We modified our laboratory equipment and successfully produced multiple $50 \mathrm{~g}$ heats of covetic copper according to the procedures outlined in the patent references. The study was led by the International Copper Association, Ltd. in consultation with Third Millennium Materials, LLC (Waverly, Ohio). In this paper, research results of density, hardness, electrical conductivity, microstructures, and carbon presence (SIMS method) of obtained casts were shown. 


\section{EXPERIMENTAL METHODS}

The base material for the melting experiments was high-purity oxygen-free high conductivity (OFHC) copper in the form of 8-mm diameter wires obtained directly from UPCAST continuous casting line. The chemical composition of the base metal is shown in Table I. For metallurgical synthesis, two kinds of carbon were used: CWZ-14 activated carbon and multiwall carbon nanotubes (IGMWNT). The properties of both carbon forms are shown in Table II.

Tests of the metallurgical synthesis method required conditions of electrical current flow and stirring of the molten copper-carbon mixture. This novel method required the design and fabrication of a special device, shown in Figure 1. Figure 1 shows the laboratory stand, which consisted of an induction furnace (1), graphite crucible (not visible, inside induction furnace), current supply device for applied current to the electrode (2), power supply for induction furnace (not labeled), stirring device (3), and inert gas supply (4). Figure 2 shows a detailed schematic of the crucible, electrode for applied current, carbon powder feed tube, stirring impeller and thermocouple. All graphite equipments (crucible, crucible lid, electrode, rotor, blender type hollow shaft) were made from the purest, commercially available, R4550 graphite. Crucible with $110 \mathrm{~mm}$ inner diameter was electrically insulated from the sidewalls so that electrical pathway was directly from the upper electrode, positioned in metal melt just beneath the surface, through the melt and to the connection at the bottom of the crucible. In all tests, temperature was measured with the use of type $\mathrm{S}$ thermocouple as shown in the Figure 2.

Several trials were necessary before the equipment operated as desired. Each trial produced casts which were designated sequentially from Cast W1 to Cast W10. In this paper, results from cast $\mathrm{W} 5, \mathrm{~W} 9$, and $\mathrm{W} 10$ are presented.

The procedure for synthesis is as follows:

- Cast W5 A mixture of the copper and nanotubes was placed in the crucible according to the proportions shown in Table III. Details of the experimental procedure are provided in Table III. The furnace was covered with a customized lid and the inert gas flow was

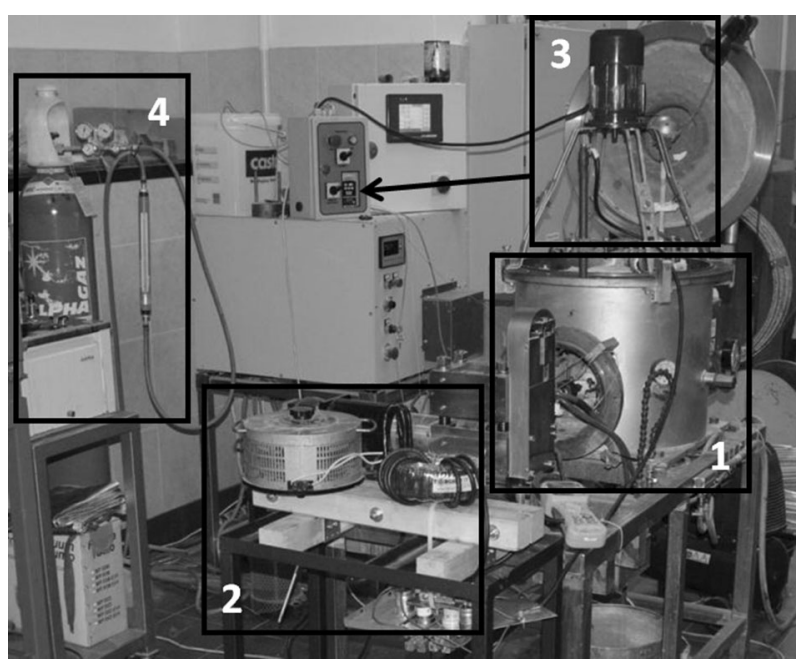

Fig. 1- Device for copper-carbon composite synthesis.

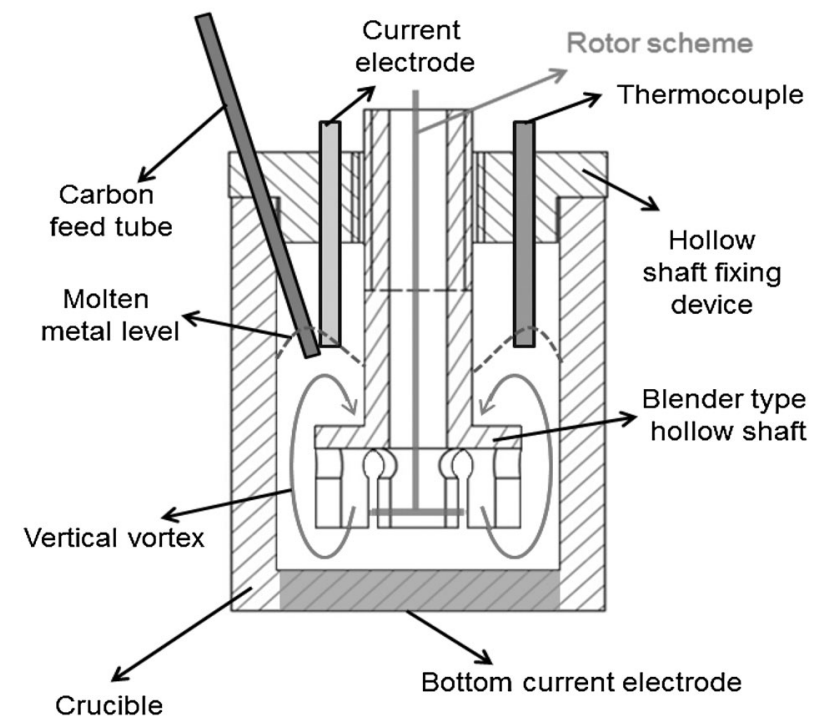

Fig. 2- Scheme of device for copper covetic synthesis with vertical vortex stirring.

Table I. Chemical Composition of High-Purity Copper Used in Synthesis of Copper-Carbon Composite

\begin{tabular}{lcccccccccccccc}
\hline $\begin{array}{l}\mathrm{Ag} \\
(\mathrm{ppm})\end{array}$ & $\begin{array}{c}\mathrm{As} \\
(\mathrm{ppm})\end{array}$ & $\begin{array}{c}\mathrm{Bi} \\
(\mathrm{ppm})\end{array}$ & $\begin{array}{c}\mathrm{Pb} \\
(\mathrm{ppm})\end{array}$ & $\begin{array}{c}\mathrm{Se} \\
(\mathrm{ppm})\end{array}$ & $\begin{array}{c}\mathrm{Sb} \\
(\mathrm{ppm})\end{array}$ & $\begin{array}{c}\mathrm{Te} \\
(\mathrm{ppm})\end{array}$ & $\begin{array}{c}\mathrm{Sn} \\
(\mathrm{ppm})\end{array}$ & $\begin{array}{c}\mathrm{Zn} \\
(\mathrm{ppm})\end{array}$ & $\begin{array}{c}\mathrm{Fe} \\
(\mathrm{ppm})\end{array}$ & $\begin{array}{c}\mathrm{Ni} \\
(\mathrm{ppm})\end{array}$ & $\begin{array}{c}\mathrm{S} \\
(\mathrm{ppm})\end{array}$ & $\begin{array}{c}\mathrm{P} \\
(\mathrm{ppm})\end{array}$ & $\begin{array}{c}\mathrm{O}_{2} \\
(\mathrm{ppm})\end{array}$ & $\begin{array}{c}\mathrm{Cu} \\
(\mathrm{Pct})\end{array}$ \\
\hline 9 & $<0.3$ & $<0.3$ & $<0.8$ & $<0.3$ & $<1$ & $<0.4$ & $<0.5$ & 1.4 & 1.7 & 1.5 & 1.2 & 0.8 & 1.5 & rem \\
\hline
\end{tabular}

Table II. Properties of Carbon Used in Synthesis of Copper-Carbon Composite

\begin{tabular}{|c|c|c|c|c|c|}
\hline \multirow[b]{2}{*}{ Type of Carbon } & \multicolumn{5}{|c|}{ Property } \\
\hline & $\begin{array}{l}\text { Particle Size } \\
(\mathrm{mm})\end{array}$ & $\begin{array}{l}\text { Iodine Number } \\
(\mathrm{mg} / \mathrm{g})\end{array}$ & $\begin{array}{c}\text { Specific Surface } \\
\text { Area }\left(\mathrm{m}^{2} / \mathrm{g}\right)\end{array}$ & $\begin{array}{l}\text { Bulk Density } \\
\qquad\left(\mathrm{g} / \mathrm{cm}^{3}\right)\end{array}$ & $\begin{array}{c}\text { Carbon Content } \\
\text { (Wt Pct) }\end{array}$ \\
\hline CWZ-14 activated carbon & 0 to 0.12 & 750 & no data & 0.29 to 0.38 & 92 \\
\hline $\begin{array}{l}\text { Multiwall carbon } \\
\text { nanotubes (IGMWNT) }\end{array}$ & 0.01 to 0.02 & no data & 60 & 0.28 & 90 \\
\hline
\end{tabular}


Table III. Cast Synthesis Parameters Used for Manufacturing of Copper Covetic materials

\begin{tabular}{|c|c|c|c|}
\hline & \multicolumn{3}{|c|}{ Cast Number } \\
\hline & W5 & W9 & W10 \\
\hline Mass of $\mathrm{Cu}(\mathrm{g})$ & 6500 & 6000 & 5000 \\
\hline Mass of $\mathrm{C}(\mathrm{g})$ & 50 & 50 & $2 \times 50$ (two parts of carbon) \\
\hline Type of $\mathrm{Cu}$ & $\mathrm{Cu} \mathrm{OFHC}$ & $\mathrm{Cu} \mathrm{OFHC}$ & $\mathrm{Cu} \mathrm{OFHC}$ \\
\hline Type of C & $\begin{array}{l}\text { Multiwall carbon } \\
\text { nanotubes (IGMWNT) }\end{array}$ & $\begin{array}{l}\text { CWZ-14 } \\
\text { activated carbon }\end{array}$ & CWZ-14 activated carbon \\
\hline $\begin{array}{l}\text { Temperature of metal at the instant } \\
\text { of rotor switching on }\left[\mathrm{K}\left({ }^{\circ} \mathrm{C}\right)\right]\end{array}$ & $1753(1480)$ & $1623(1350)$ & $1649(1376)$ \\
\hline Rotor speed (rps) & 5 & 20 & 20 \\
\hline Duration of stirring $(\mathrm{min})$ & 20 & 5 & 5 \\
\hline $\begin{array}{l}\text { Temperature of metal at the instant } \\
\text { of switching current on }\left[\mathrm{K}\left({ }^{\circ} \mathrm{C}\right)\right]\end{array}$ & $1693(1420)$ & $1625(1352)$ & $\begin{array}{l}1652 \text { (1379) (first part of carbon) } \\
1639 \text { (1366) (second part of carbon) }\end{array}$ \\
\hline Current (A) & 110 & 150 & 150 \\
\hline Duration of current flow (min) & 40 & 3 & 3 \\
\hline $\begin{array}{l}\text { Temperature of metal after the current } \\
\text { switching off }(1 \mathrm{~min})\left[\mathrm{K}\left({ }^{\circ} \mathrm{C}\right)\right]\end{array}$ & $1693(1420)$ & $1553(1280)$ & $\begin{array}{l}1629 \text { (1356) (first part of carbon) } \\
1624 \text { (1351) (second part of carbon) }\end{array}$ \\
\hline Residual mass of $\mathrm{C}$ after process $(\mathrm{g})$ & 43 & 0 & 0 \\
\hline Type of vortex & horizontal & vertical & vertical \\
\hline
\end{tabular}

turned on. Next, the furnace was switched on and when the copper was melted and temperature stabilized, the mixer was switched on as well (horizontal vortex-classic mixer with four blades). To provide continuous temperature stabilization, induction unit was left turned on for the entire experiment duration. While the copper carbon mixture was being stirred, the current flow to the electrode was switched on. Electrical current flow was between current electrode and the bottom of crucible. At the end of process, all devices were switched off and molten metal was left for solidification.

- Casts W9 and W10 The quantities of copper shown in Table III were placed in the crucible, which was sealed with a customized lid. Inert gas flow was switched on and furnace was switched on as well. After the copper was melted, stirring and current flow were switched on and carbon was added (cast W9-one portion of $50 \mathrm{~g}$, cast W10-two portions of $50 \mathrm{~g}$ ). Carbon was added directly into the zone of current flow with the use of a special graphite lance. In W10, the current was applied for 3 minutes and carbon was added in two batches during this time. During the first carbon addition, the molten metal temperature dropped $296 \mathrm{~K}\left(23{ }^{\circ} \mathrm{C}\right)$ from $1652 \mathrm{~K}$ to $1629 \mathrm{~K}\left(1379{ }^{\circ} \mathrm{C}\right.$ to $\left.1356^{\circ} \mathrm{C}\right)$, the temperature then recovered to $1639 \mathrm{~K}\left(1366^{\circ} \mathrm{C}\right)$ and dropped $288 \mathrm{~K}$ to $1624 \mathrm{~K}\left(15^{\circ} \mathrm{C}\right.$ to $\left.1351{ }^{\circ} \mathrm{C}\right)$ during the second addition. During current flow in W10 synthesis, mixture temperature drop of $298 \mathrm{~K}\left(25^{\circ} \mathrm{C}\right.$ ) (first part of carbon) and $288 \mathrm{~K}\left(15^{\circ} \mathrm{C}\right)$ (second part of carbon) was observed. During synthesis, the stirring device for vertical vortex and electrical current flow between electrodes were used. After the end of the synthesis the molten metal was left in the crucible and solidified in place under inert gas atmosphere. Still working stirring device was left till the end of the trial (current electrode and carbon feed tube were pulled out just before metal solidification).
Tests were carried out using the following instruments and methodology:

- Density was measured with the use of Mettler Toledo AB104-s in accordance with ISO 1183-1:2004.

- Sample size: $\phi 8 \times 10 \mathrm{~mm}$,

- Number of tests: 6 ,

- Type of final value: arithmetic mean.

- Chemical composition was measured with the use of optical emission spectroscopy (OES)-SPECTROLAB - LAB M10, LECO TC500 in accordance with PN-EN 15079:2009P

- Sample size: $\phi 20 \times 10 \mathrm{~mm}$,

- Number of tests: 1 .

- Hardness (HV5) was measured with the use of hardness testing machines-Tukon $2500 \mathrm{Knoop} /$ Vickers in accordance with ISO 6507-1:2005.

- Sample size: $\phi 20 \times 10 \mathrm{~mm}$,

- Number of tests: 2 per sample (indentation every $2 \mathrm{~mm}$ on sample diameter),

- Type of final value: arithmetic mean.

- Electrical conductivity was measured with the use of SigmaTest 2.069 Foerster device in accordance with ASTM E1004-09.

- Sample size $\phi 20 \times 10 \mathrm{~mm}$,

- Number of tests: 6 ,

- Type of final value: highest measured.

- Macrostructure analysis was performed with the use of Olympus GX51 optical microscope.

- Microstructure analysis was performed with the use of transmission electron microscope JEOL JEM-2010 ARP with EDS adapter Oxford-Link.

- Distribution of carbon in sample was measured with the use of Secondary Ion Mass Spectroscopy method on TOF- 
SIMS 5 apparatus (mode: dual beam, sputter gun: Cs $70 \mathrm{nA} @ 1 \mathrm{keV}$ sputter crater size $300 \times 300 \mu \mathrm{m}$, analysis gun: Bi 1.9 pA@30 keV, analysis area $100 \times 100 \mu \mathrm{m})$.

- Measured depth: $2500 \mathrm{~nm}$.

\section{RESEARCH RESULTS}

During synthesis of covetic, casts with cylindrical shape (diameter $110 \mathrm{~mm}$ ) were obtained and shown in Figure 3. Cast W5 had surface porosity, while casts W9 and W10 had good (smooth) surface. Additional research results (not described in this paper) confirmed that surface quality depends on (a) the type of mixing device used for stirring and (b) the method of carbon addition. A mixing device that creates a vertical vortex increases the $\mathrm{Cu}-\mathrm{C}$ mixture stirring intensity which allows for achievement of better surface quality of casts. The ingots were sectioned for testing.

\section{CHEMICAL COMPOSITION}

Chemical analysis results are shown in Table IV. An increased content of $\mathrm{Fe}, \mathrm{Ni}$, and $\mathrm{S}$ in the casts came from known impurities in the carbon materials. Casts W9 and W10 had an increased content of Fe (5.7 ppm-W9, $10.2 \mathrm{ppm}-\mathrm{W} 10)$. Cast W5 had an increased content of $\mathrm{Ni}(16.1 \mathrm{ppm})$. All experimental heats exhibited increased sulfur levels, from $1.2 \mathrm{ppm}$ in the base metal up to 5.6 to
$7.6 \mathrm{ppm}$. The 8 to $9 \mathrm{ppm}$ levels of Ag were consistent with the base metal level of $9 \mathrm{ppm}$. The very low level of $\mathrm{O}_{2}$ $\max 2 \mathrm{ppm}$ is consistent with the $\mathrm{Cu}$ OFHC base material. Maximum carbon content value $-\mathrm{C}_{\max }$, attached in Table IV is consistent with the amount of carbon added to the molten metal during each trial.

\section{PROPERTIES OF SYNTHESIZED COVETIC MATERIALS}

Research results of density, Vickers hardness (HV5), and electrical conductivity are shown in Table V. Cast W5 had density $8.932 \mathrm{~g} / \mathrm{cm}^{3}$ which is the density of measured $\mathrm{Cu}$ OFHC base material. Casts W9 and W10 had lower density than $\mathrm{Cu}$ OFHC base material (W9-8.906 g/ $\mathrm{cm}^{3}, \mathrm{~W} 10-8.914 \mathrm{~g} / \mathrm{cm}^{3}$ ). Hardness tests indicated that cast W5 had the lowest average hardness (HV5-42.8) and W10 the highest average hardness (HV5-58.1). Tests results of electrical conductivity of casts show that sample W5 had conductivity at the level of $59.4 \mathrm{MS} / \mathrm{m}$ (102.4 pct IACS), W9 $58.84 \mathrm{MS} / \mathrm{m}$ (101.4 pet IACS) and W10-58.1 MS/m (100.2 pct IASC). However, it should be noted that both electrical conductivity and hardness tests results may be influenced by the micro-porosity of produced samples which occurred in casts volume. Nevertheless surprising is the fact that sample W5 has relatively high electrical conductivity despite of high level of contamination with Ni. Cast W9 and W10 contaminated with Fe and S had lower electrical conductivity than the base material used

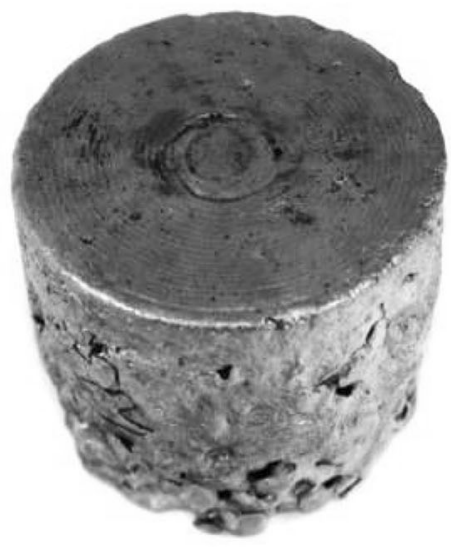

(a)

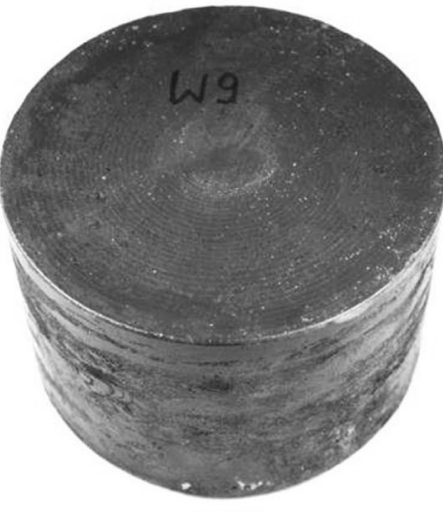

(b)

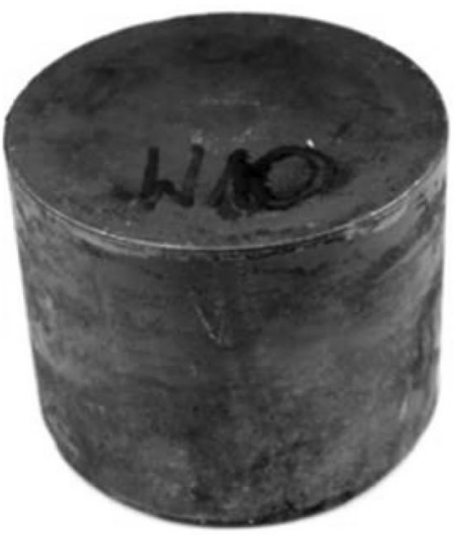

(c)

Fig. 3- Covetic casts - diameter $110 \mathrm{~mm}: a \mathrm{~W} 5, b \mathrm{~W} 9$, and $c \mathrm{~W} 10$.

Table IV. Chemical Composition of Casts W5, W9, and W10

\begin{tabular}{|c|c|c|c|c|c|c|c|c|c|c|c|c|c|c|c|c|}
\hline $\begin{array}{l}\text { Cast } \\
\text { Number }\end{array}$ & $\begin{array}{c}\mathrm{Ag} \\
(\mathrm{ppm})\end{array}$ & $\begin{array}{c}\text { As } \\
(\mathrm{ppm})\end{array}$ & $\begin{array}{c}\mathrm{Bi} \\
(\mathrm{ppm})\end{array}$ & $\begin{array}{c}\mathrm{Pb} \\
(\mathrm{ppm})\end{array}$ & $\begin{array}{c}\mathrm{Se} \\
(\mathrm{ppm})\end{array}$ & $\begin{array}{c}\mathrm{Sb} \\
(\mathrm{ppm})\end{array}$ & $\begin{array}{c}\mathrm{Te} \\
(\mathrm{ppm})\end{array}$ & $\begin{array}{c}\mathrm{Sn} \\
(\mathrm{ppm})\end{array}$ & $\begin{array}{c}\mathrm{Zn} \\
(\mathrm{ppm})\end{array}$ & $\begin{array}{c}\mathrm{Fe} \\
(\mathrm{ppm})\end{array}$ & $\begin{array}{c}\mathrm{Ni} \\
(\mathrm{ppm})\end{array}$ & $\begin{array}{c}\mathrm{S} \\
(\mathrm{ppm})\end{array}$ & $\begin{array}{c}\mathrm{P} \\
(\mathrm{ppm})\end{array}$ & $\begin{array}{c}\mathrm{O}_{2} \\
(\mathrm{ppm})\end{array}$ & $\begin{array}{c}\mathrm{C}_{\max } \\
(\mathrm{ppm})\end{array}$ & $\begin{array}{c}\mathrm{Cu} \\
(\mathrm{ppm})\end{array}$ \\
\hline W5 & 8.74 & $<0.3$ & $<0.3$ & $<0.8$ & $<0.3$ & $<1$ & $<0.4$ & $<0.5$ & 1.31 & 2.53 & 16.08 & 7.6 & 1.9 & 0.6 & 7692 & rem \\
\hline W9 & 8.04 & 0.63 & $<0.3$ & $<0.8$ & $<0.3$ & $<1$ & $<0.4$ & $<0.5$ & 0.93 & 5.69 & 1.33 & 5.59 & 1.1 & 2.1 & 8333 & rem \\
\hline W10 & 8.59 & $<0.3$ & $<0.3$ & $<0.8$ & $<0.3$ & $<1$ & $<0.4$ & $<0.5$ & 1.14 & 10.15 & 1.51 & 6.71 & 0.85 & 1.8 & 20000 & rem \\
\hline $\begin{array}{l}\mathrm{Cu} \text { base } \\
\text { material }\end{array}$ & 9 & $<0.3$ & $<0.3$ & $<0.8$ & $<0.3$ & $<1$ & $<0.4$ & $<0.5$ & 1.4 & 1.7 & 1.5 & 1.2 & 0.8 & 1.5 & - & rem \\
\hline
\end{tabular}


for synthesis. Nevertheless, it should be noted that each ppm of $\mathrm{Fe}$, $\mathrm{Ni}$, and $\mathrm{S}$ has very negative effect for electrical properties of copper and high electrical conductivity copper alloys. Therefore, it is very surprising that obtained materials had relatively high electrical conductivity which normally should be at the level of $57 \mathrm{MS} / \mathrm{m}$ or even lower.

\section{MICROSTRUCTURE AND SIMS ANALYSIS}

Photos of cast structures are shown in Figure 4. Test were carried out on samples cut from obtained casts from the center of casting axis. Preparation of samples included macroetching with the use of nitric acid (diluted with water to a 50 to 50 pct ratio). Research results shown that all samples had dendrite structure which is typical for standard casts (low amount of relatively big grains). The pictures also indicate grain boundary areas and dendrite morphology of samples.

Analysis methods of carbon content in copper are very difficult and little known. Quantitative determination of the carbon content in copper using EDS (EDX) or XPS methods is very problematic for samples with low quantities of carbon. In those types of tests carbon

Table V. Properties of Casts W5, W9, and W10

\begin{tabular}{lcccc}
\hline Cast Number & Density $\left(\mathrm{g} / \mathrm{cm}^{3}\right)$ & Hardness $(\mathrm{HV} 5)$ & Electrical Conductivity $(\mathrm{MS} / \mathrm{m})$ & IACS $($ Pct $)$ \\
\hline Cu base material & 8.932 & 75.3 & 58.83 & 101.4 \\
W5 & 8.932 & 42.8 & 59.4 & 102.4 \\
W9 & 8.906 & 55.6 & 58.84 & 101.4 \\
W10 & 8.914 & 58.1 & 58.1 & 100.2 \\
\hline
\end{tabular}
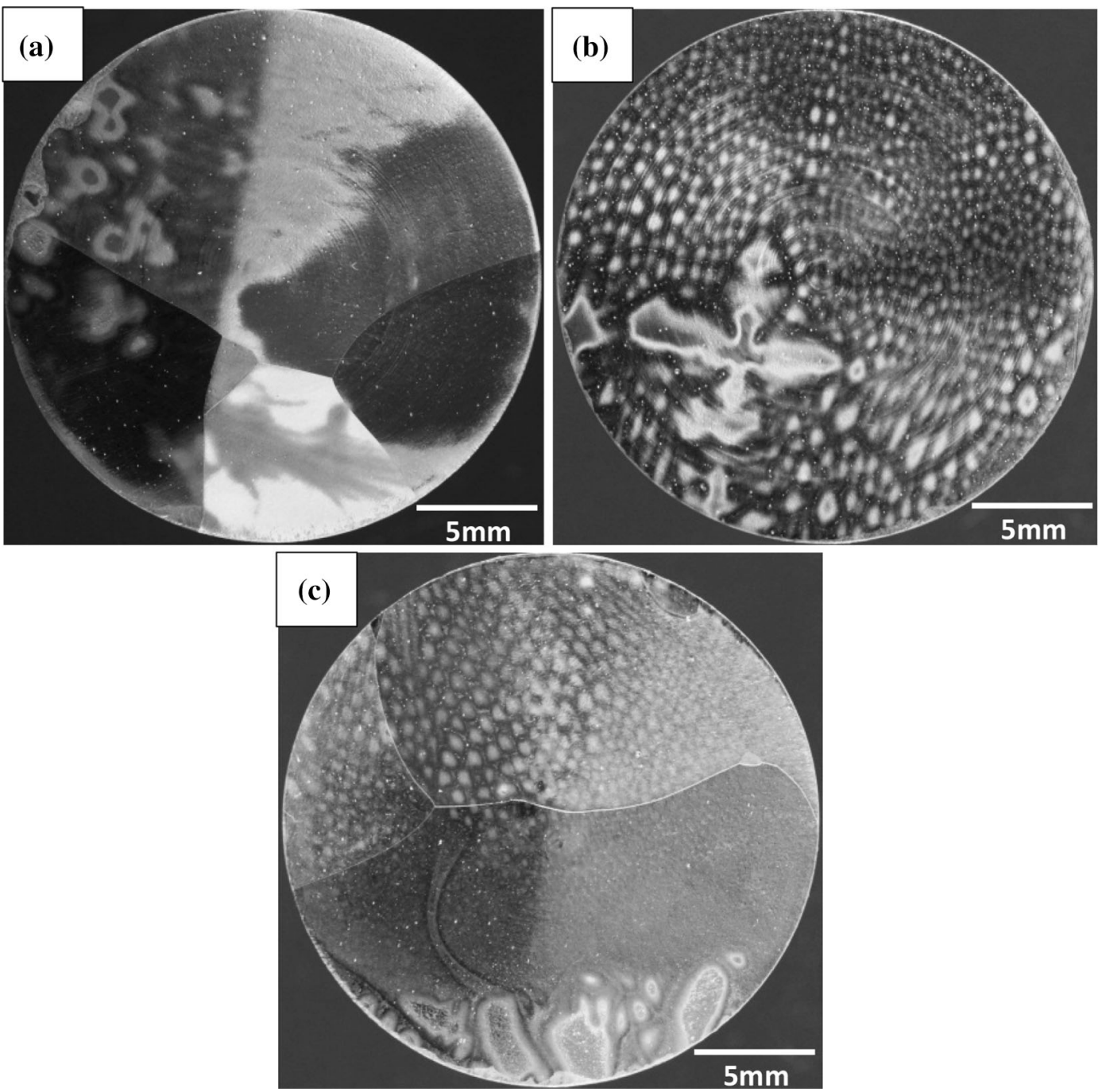

Fig. 4 - Cross-section macrostructures of covetic (sample diameters-20 mm): $a \mathrm{~W} 5, b \mathrm{~W} 9$, and $c \mathrm{~W} 10$. 

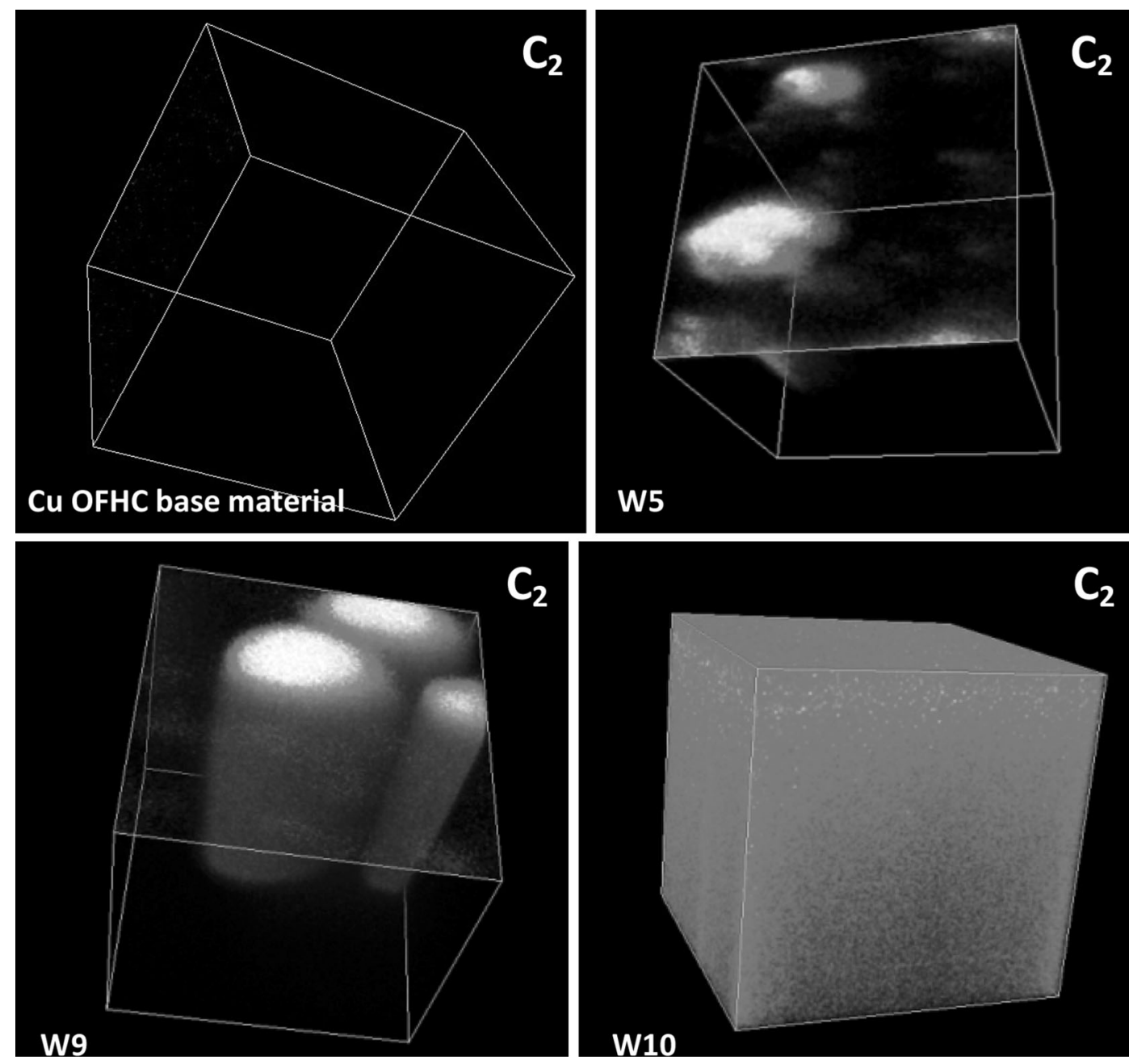

Fig. 5- SIMS analysis of carbon presence in copper carbon-composites and CuOFHC base material - the brighter the color in the cube the higher the level of $\mathrm{C}_{2}$ presence.

will be always present in the microscope chamber and will give "false" carbon peaks on EDS (EDX) or XPS diagram. Also performed during the experiment, carbon measurements with the use of Leco method (ASTM E1019-08) did not give a good result (intense discrepancy of carbon content between the individual tests). SIMS method on the other hand gives a good result in qualitative determination of carbon presence in copper but cannot be used for quantitative determination. Using the SIMS method, we can compare carbon presence (ion yield) between different samples.

Research results of carbon presence and distribution in produced casts using SIMS method show that in sample cast W5 very small amounts of carbon were detected whereas in the samples from W9 and W10 there was much more carbon (in the cast W9 in the form of columns and in the cast W10 it is evenly distributed in the sample volume). Figure 5 shows the visualization of carbon content in W5, W9, W10 casts samples $\left(\mathrm{C}_{2}\right.$ presence is marked in white). Reference point is $\mathrm{Cu}$ OFHC base material where we do not observe any $\mathrm{C}_{2}$ presence. Figure 6 shows the relative magnitudes of ion yields $\mathrm{Cu}, 65 \mathrm{Cu}, \mathrm{C}, \mathrm{C}_{2}, \mathrm{CuC} v \mathrm{~s}$ depth of W9 and W10 samples.
Figure 7 presents photos of microstructure and diffraction of W9 and W10 samples. Research results of TEM microstructure show that in the structure of casts W9 and W10 there was a second phase. In the picture A and $\mathrm{B}$, visible dark features possibly correspond to copper-carbon crystalline particles. In the picture B also dislocation structures were being observed. Visible in the picture B individual white particle is a void that comes from an inclusion that was dissolved during the sample preparation. Diffraction pictures confirm that close to the $\mathrm{Cu}$ pattern there is a second pattern which actually may come from carbon structure incorporated into $\mathrm{Cu}$ lattice (possibly a graphene-type carbon structure). Similar research results can be found in Reference 17. In addition, a strong stretch of diffraction spots along arcs indicates a large distortion of crystalline structure.

\section{CONCLUSIONS AND RESEARCH RESULTS DISCUSSION}

(1) The researchers have succeeded in the first independent replication of the results of Shugart and 


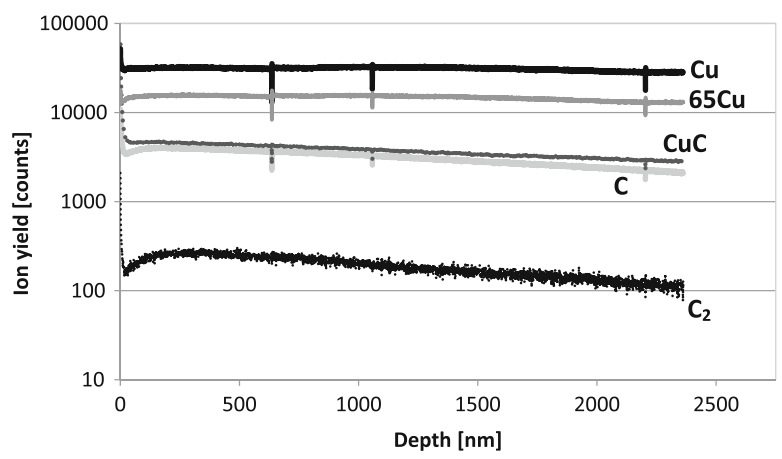

(a)

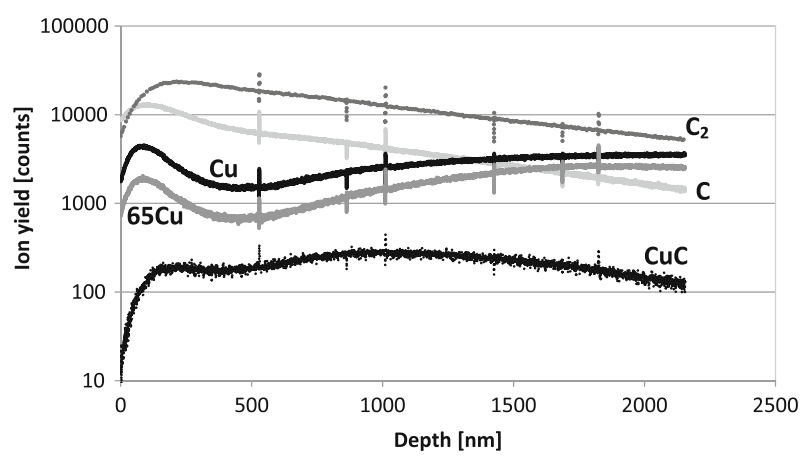

(b)

Fig. 6- Ion yield of $\mathrm{Cu}, 65 \mathrm{Cu}, \mathrm{C}, \mathrm{C}_{2}$, and $\mathrm{CuC}$ in copper-carbon composite samples: $a \mathrm{~W} 9$ and $b \mathrm{~W} 10$.
Scherer, ${ }^{[7,8]}$ who invented a process for incorporating large amounts of carbon into copper. The resulting metal matrix composite is stable in the melt, and may involve a previously unknown type of chemical bonding between carbon and metal that in the end do not change the basic metal density.

(2) It was found that obtained casts have density at the same level as $\mathrm{Cu}$ OFHC base material. This is very interesting and unusual taking into consideration that amounts of carbon added to the molten metal were up to $2 \mathrm{wt}$ pct (during the W10 trial). This result is not consistent with the rule of mixtures but similar research results can be also found in Reference 18 .

(3) The electrical conductivity of obtained copper-carbon composite is relatively high considering the level of contamination with $\mathrm{Fe}, \mathrm{Ni}$, and $\mathrm{S}$. These elements in normal conditions are the reason of sharp drop of electrical conductivity of $\mathrm{Cu}$ OFHC below 100 pet IACS.

(4) SIMS analysis shows that inside obtained casts there is carbon. Cast W10 has carbon homogeneously located in the volume of measured sample. In the cast W9, carbon is located in tested sample in form of columns. In the cast W5, carbon content is the lowest of all.

(5) TEM analysis shows that in the structure of casts W9 and W10 a second phase is present (visible additional pattern that do not correspond to $\mathrm{Cu}$
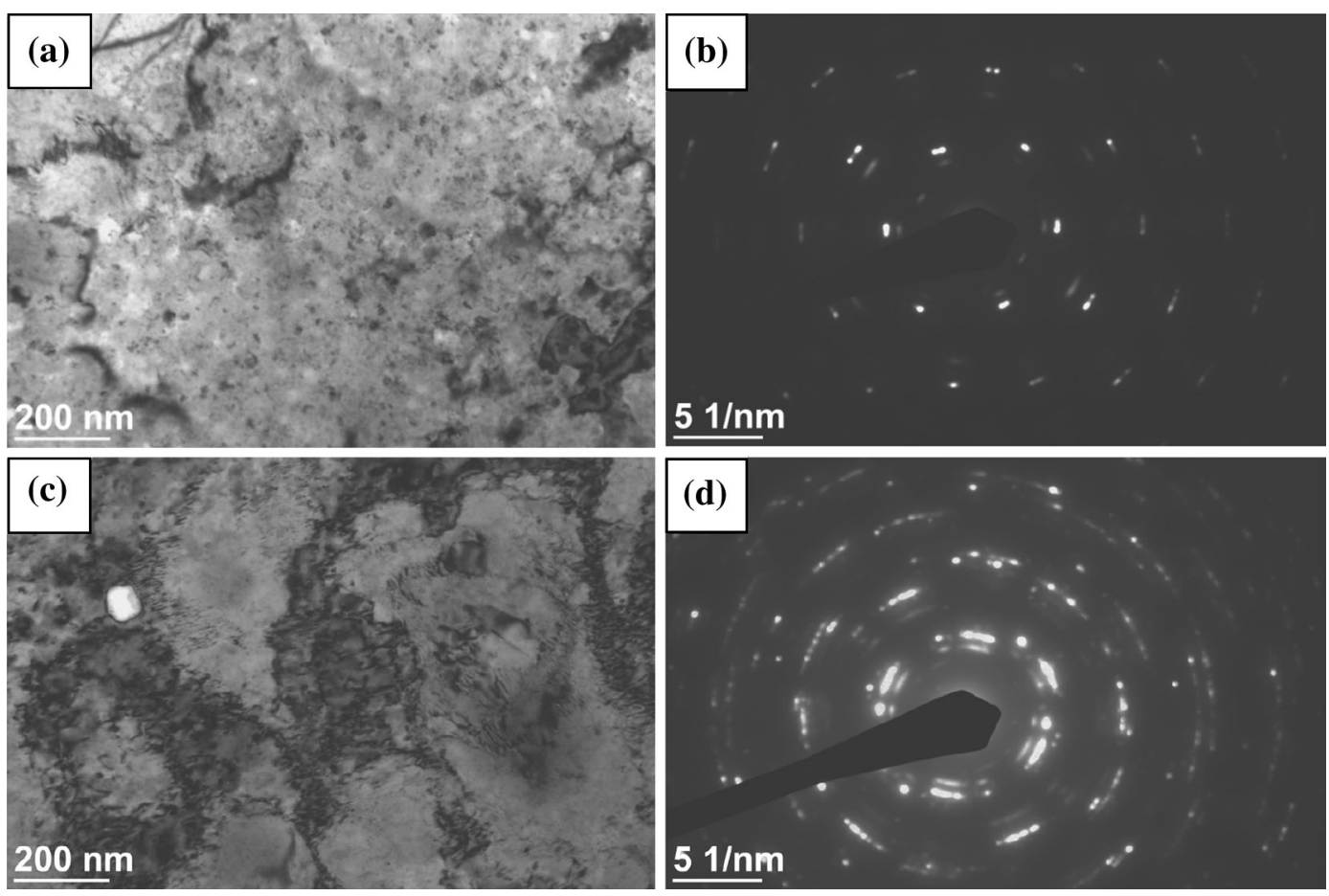

Fig. 7- Microstructure analysis of synthesized copper-carbon composites: $a$ microstructure of W9, $b$ diffraction of W9, $c$ microstructure of $\mathrm{W} 10$, and $d$ diffraction of $\mathrm{W} 10$. 
pattern). Diffraction patterns show strong stretch of diffraction spots. Arcs indicate a large distortion of crystalline structure.

\section{ACKNOWLEDGMENTS}

The authors would like to express their gratitude for the financial support provided by International Copper Association, Ltd. for this study, and to Third Millennium Materials, LLC for their advisory role in this project.

\section{OPEN ACCESS}

This article is distributed under the terms of the Creative Commons Attribution License which permits any use, distribution, and reproduction in any medium, provided the original author(s) and the source are credited.

\section{REFERENCES}

1. J.P. Tu, Y.Z. Yanga, L.Y. Wanga, X.C. Ma, and X.B. Zhang: Tribol. Lett., 2011, vol. 10, pp. 363-70.

2. A.K. Shukla, N. Nayan, S.V.S.N. Murty, S.C. Sharma, K. Mondal, and P.P. Sinha: Mater. Sci. Forum, 2012, vol. 710, pp. 285-90.

3. Ch. Guiderdoni, C. Estournès, A. Peigney, A. Weibel, V. Turq, and Ch. Laurent: Carbon, 2011, vol. 49, pp. 4535-43.
4. T.S. Koltsova, L.I. Nasibulina, I.V. Anoshkin, V.V. Mishin, E.I. Kauppinen, O.V. Tolochko, and A.G. Nasibulin: J. Mater. Sci. Eng., 2012, vol. 2 (4), pp. 240-46.

5. D. Geng, B. Wu, Y. Guo, L. Huang, Y. Xue, J. Chen, G. Yu, L. Jiang, W. Hu, and Y. Liu: Proc. Natl. Acad. Sci. USA, 2012, vol. 109 (21), pp. 7992-96.

6. Y. Jang, S. Kim, S. Lee, M. Kim, and M. Um: Compos. Sci. Technol., 2005, vol. 65, pp. 781-84.

7. J.V. Shugart and R.C. Scherer: Patent nr. US2012/0009110 A1.

8. J.V. Shugart and R.C. Scherer: Patent nr. US 2010/0327233 A1.

9. K. Jagannadham: J. Vac. Sci. Technol. B, 2012, vol. 30, pp. 03D109-1-03D109-9.

10. S.R. Bakshi, D. Lahiri, and A. Agarwal: Int. Mater. Rev., 2010, vol. 55 (1), pp. 41-64.

11. T.H. Nayfeh and A.M. Wiederholt: Patent nr. US 2012/0152480.

12. G.A. Lopez and E.J. Mittemeijer: Scripta Mater., 2004, vol. 51 (1), pp. 1-5.

13. R.C. Scherer, J.V. Shugart, and K. Lafdi: New Class of Metallic Nanocomposites: Nanocarbon Metals, Materials Science \& Technology 2009 , Pittsburgh, PA, 25 October 2009.

14. D.R. Forrest, L. Brown, L. Salamanca-Riba, J. Wolk, P. Joyce, and J. Zhang: Nanoscale Carbon in Metals for Energy Applications, Materials Science \& Technology 2011, Columbus, OH, 19 October 2011.

15. D.R. Forrest, L. Brown, P. Joyce, A. Mansour, L. SalamancaRiba, and I. Jasiuk: Nanocarbon metals, Materials Science \& Technology 2012, Pittsburgh, PA, 10 October 2012.

16. L. Brown, P. Joyce, D. Forrest, and J. Wolk: Physical and Mechanical Characterization of a Nanocarbon Infused AluminumMatrix Composite, Proceedings of the SAMPE Fall Technical Conference, Ft. Worth, TX, 17-20 October 2011.

17. L. Salamanca-Riba, A. Herzing, A. Mansour, A. Hall, D.R. Forrest, M. LeMieux, and J. Shugart: A New Type of Carbon Nanostructure Formed within a Metal-Matrix, Proceedings of Nanotech Conference and Expo 2012, 18-21 June 2012, CRC Press, Santa Clara, CA.

18. D.R. Forrest, I. Jasiuk, L. Brown, P. Joyce, and L. SalamancaRiba: Novel Metal Matrix Composites with Integrally Bound Nanoscale Carbon, Proceedings of Nanotech Conference and Expo 2012, 18-21 June 2012, CRC Press, Santa Clara, CA.

19. B.C. Yoo and J.W. Byeon: Adv. Mater. Res., 2012, vol. 590. 